\title{
S. Omirbayev
}

Doctor of Economics, Professor, First Vice-Rector serik.omirbayev@astanait.edu.kz,orcid.org/0000-0001-7643-3513 Astana IT University, Kazakhstan
A. Mukhatayev
Candidate of Pedagogical Sciences, Associate Professor, Director of the Department of Strategy and Corporate Governance aidos.mukhatayev@astanait.edu.kz,orcid.org/0000-0002-8667-3200 Astana IT University, Kazakhstan
A. Biloshchytskyi
Doctor of Technical Sciences, Professor,
Vice-Rector for Science and Innovation
a.b@astanait.edu.kz, orcid.org/0000-0001-9548-1959
Astana IT University, Kazakhstan
Professor of Information Technologies Department
Kyiv National University of Construction and Architecture, Ukraine
K. Kassenov
Master of Pedagogical Sciences, Chief Academic Compliance Officer khanat.kassenov@astanait.edu.kz, orcid.org/0000-0002-7555-4919 Astana IT University, Kazakhstan

\section{NATIONAL MODEL OF THE QUALITY ASSURANCE OF EDUCATION IN KAZAKHSTAN: FORMAT, TOOLS, AND REGULATORY MECHANISMS}

\footnotetext{
Abstract. In this article, the authors consider the quality assurance system at the national level. The normative legal acts of the Republic of Kazakhstan contributing to the development of quality assurance at the institutional level are analyzed. The structure of state management of the quality assurance system of higher education is given. The authors show the implementation of the process of external and internal quality assurance in the country. At the same time, the internal quality assurance system is based on the principles of quality assurance and on the policy and standards of internal quality assurance, which are developed by the higher education institution independently, but on the basis of ESG. The design of the national quality assurance model is presented in a three-dimensional image. The basis of the National Model of Quality assurance of Higher Education in Kazakhstan (NMQAHE) is the system of internal quality assurance. The indicator of achievement of academic quality by the internal quality assurance system is the academic reputation of a higher educational institution. The answer to the question is given due to what the successful functioning of the national quality assurance model is achieved.

Key words: quality assurance, higher education system, internal quality assurance, external quality assurance, academic reputation.

\section{Introduction}

The modern problems of the National Quality Assurance system in higher education are of great relevance for higher educational institutions of Kazakhstan since the current period of
} 
modernization of the higher education system involves both structural changes and updating the content of educational programs and learning technologies. This is primarily due to two important developments - the development of the National project "Quality Education "Educated Nation" [1] and the adoption of the Concept of Lifelong Learning (Continuing Education) [2]. Both documents are directly related to the Quality assurance system of higher education.

Kazakhstan, as a full member of the European Higher Education Area, forms its system of Quality assurance of higher education in accordance with European approaches, namely on the basis of Standards and Guidelines for quality assurance in the EHEA (ESG). This is the implementation in Kazakhstani education not only of the obligations undertaken, but also meets the internal needs of education and national interests.

It should be noted that Kazakhstan's national model of quality assurance of higher education is completely based on ESG and has a similar three-level structure (Table 1).

Table 1. Structure of the National QA system of the Republic of Kazakhstan in higher education

\begin{tabular}{|l|l|}
\hline \multicolumn{1}{|c|}{ ESG } & \multicolumn{1}{c|}{ Kazakhstan } \\
\hline Standards for internal quality assurance & Standards for internal quality assurance \\
\hline Standards for external quality assurance & Standards for external quality assurance \\
\hline Standards for Quality Assurance agencies & State administration for the quality assurance system \\
\hline
\end{tabular}

The foundations of QA at the National level are laid down in the Article 30 of the Constitution of the Republic of Kazakhstan that establishes the state and compulsory standards of education, and the activities of any educational institutions must meet these standards [3].

In accordance with the Law of the Republic of Kazakhstan "On Education", the state control for the quality of education is ensured by creating and ensuring the functioning of a national system for assessing the quality of education (Article 8). The authorized body, the competence of which includes this function, is the Ministry of Education and Science of the Republic of Kazakhstan. The Committee for Quality Assurance in Education and Science, functioning within the Ministry of Education and Science, is an agency that performs the functions of implementing State policy in the field of Quality assurance of education and science, as well as control and implementation functions.

On July 4, 2018, the Law of the Republic of Kazakhstan "On Amendments and Additions to Certain Legislative Acts of the Republic of Kazakhstan on expanding the academic and administrative independence of higher education institutions" [4] was adopted. The level of autonomy of universities, accompanied by accountability mechanisms. The transition from quality control to quality assurance system was carried out. For this reason, the Committee for Control in the field of Education and Science was transformed into the Committee for Quality Assurance in Education and Science.

Education quality management is aimed at implementing a unified state policy in the field of education and includes state and institutional structures that make up a single national system for assessing the quality of education, the rationality of the use of funds allocated to finance education, and in general the effectiveness of the functioning of the education system.

\section{Research methods}

In the course of the research, a range of theoretical methods were applied: content analysis of the conceptual apparatus; a comparative analysis of regulatory legal acts of countries; study and generalization of advanced pedagogical experience; synthesis of the results of analytical activity. 
When constructing a National model of the Education Quality Assurance system, projective methods, including the modeling method, were used.

The authors relied on the results of scientific research of scientists and the best international experience of different countries, regulatory documents in the field of education of the Republic of Kazakhstan, and the recommendations of the Bologna Process.

\section{Literature review}

The problem of research on the national quality assurance system is the subject of research by scientists from different countries. In recent years, scientists have been studying the quality assurance system of education, forms, and methods of quality assurance, paying special attention to the study of trends in the development of the quality assurance system of higher education in European and American countries, paying special attention and studying their leading ideology of quality assurance of education, forms, and specific methods, getting a lot of inspiration.

For example, the Chinese researchers [5] has proved the effectiveness of the higher education quality assurance system based on EFQM model as well as its flexibility and practicality, which can be used in our country's higher education quality assurance system, by which can give direction for education system reform and provide measures, in this way it can provide more high-quality talents which are conducive for national and social development.

The educators from Transbaikal State University [6] studied the Regulatory and Methodological Changes in the System of Higher Education Quality Assurance. They proposed that the focus should be made on assurance of the following conditions: adherence of the top management to the innovation processes; inclusion of orientation to innovations in the "Code of corporate culture"; informing the personnel of the organization about the document drafts, the enactment of which will ensure regulatory and methodological changes in certain activities; participation of the organization in discussing the introduced drafts of documents, proposal of corrections in them; and etc.

Ensuring quality of education Kazakhstan HEls develops the national system in accordance with ESG. The final report of the project Steering Group [7] stated that in Kazakhstan the ESG is regarded more as a practical tool. It is known that the ESG was more than inspirational to the development of a national external QA system. Thus, the ESG entered into internal QA via external QA. They also concluded that impact can be seen in processes for both internal and external $Q A$ and at the national and system levels.

O. Bliznyuk proposed [8] that a university can be guided by several substantive aspects of the concept of "quality of education" when forming its own quality system. The management of the university is designed to solve the problem of the growth of the internal culture of quality, and not to "manage the culture". The solution to this problem is complicated by the fact that it largely depends on the understanding of quality (and it can be different), which leads to ambivalent situations.

Koforidua Polytechnic scientist [9] revealed that their university has made efforts to develop internal quality assurance structures and institutional-wide quality assurance policies. But the Polytechnics have not been very successful in establishing a quality culture, weaknesses and challenges still remain. Among others, the study recommends that the Polytechnics should not copy wholesale from the universities' and international practices but should select quality assurance practices relevant to the Polytechnic context. This suggests the need to focus on the national context when establishing a national quality assurance system.

In 2018 the Center of Bologna process and academic mobility of the Ministry of education and science of the Republic of Kazakhstan published the Analytical report that suggested to strengthen the internal quality assurance system, Kazakh universities are recommended 
to strengthen the qualitative composition of academic services and structural units. It is necessary to conceptually revise the internal documents and regulations governing the issues of academic and scientific policy of the university. At the same time, this work should be carried out in the context of a new regulatory framework within the framework of institutional, academic, and managerial autonomy of Kazakhstani universities [10].

\section{Overview of the National Education Quality Assurance system of Kazakhstan}

\section{State management of the quality assurance system of higher education}

The policy of quality assurance of higher education is carried out not only at the level of universities, but also at the national level through regulatory mechanisms. The state forms a national model of quality assurance, which should be stable, transparent, and understandable to each subject of the educational process. The need for state regulation of the quality assurance system is since the state protects the interests of citizens in obtaining affordable and high-quality higher education.

State management for the quality assurance system of higher education is based on the principles of trust and sustainability and established on three components: minimum requirements for the content of education (State compulsory standard; model educational programs of general education disciplines); minimum requirements for implementation (Qualification requirements for educational activities) and requirements for accreditation agencies (Fig. 1).

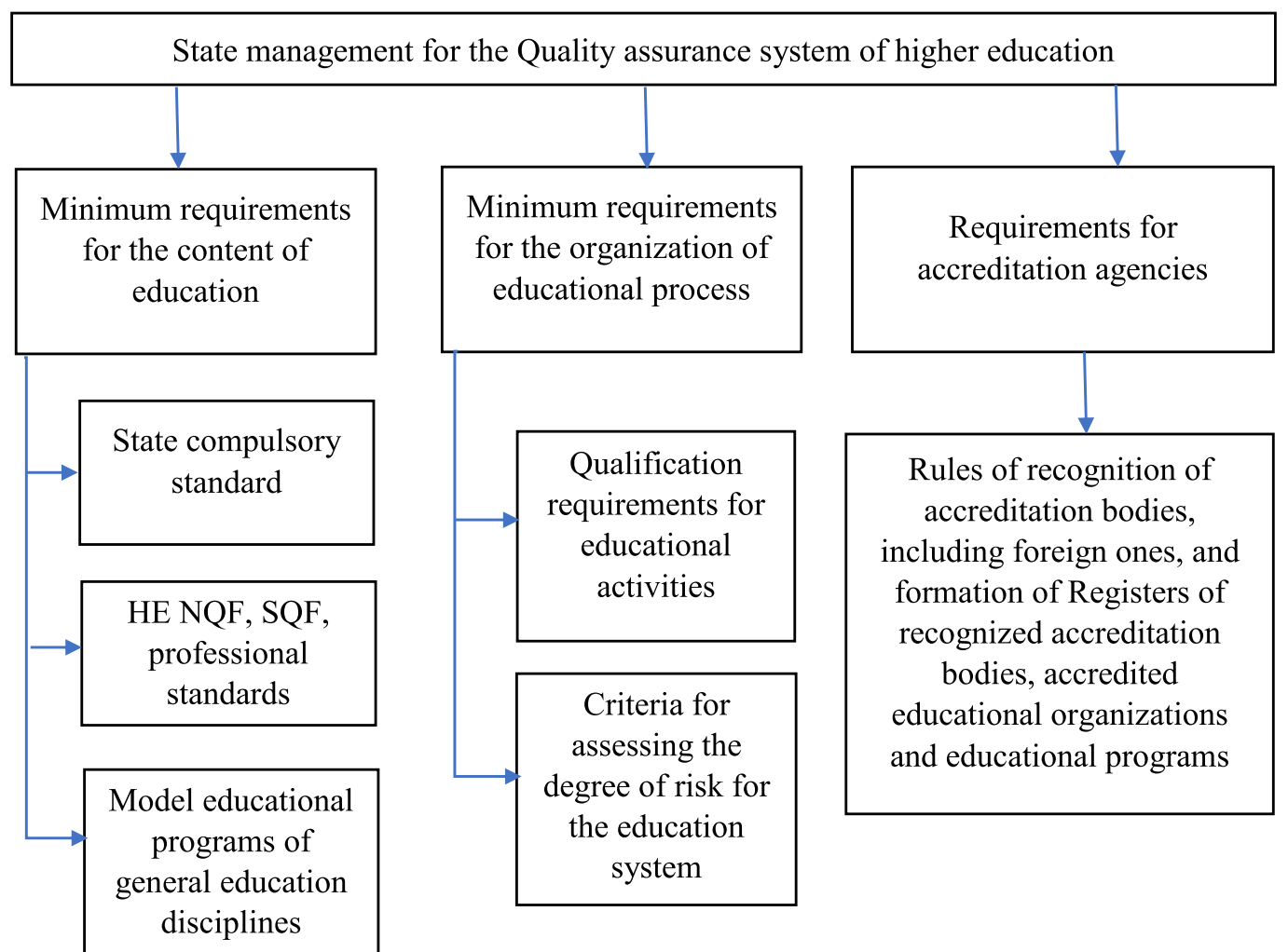

Fig. 1. Structure of the state administration for the quality assurance system of higher education

According to the Law "On Education", the state regulation in the field of education is aimed at creating conditions that ensure the implementation of constitutional rights to education and ensuring the high quality of educational services provided by educational organizations and is carried out through legal support, quality management of education, standardization, and control (Article 54). To determine the minimum requirements for the content of education, by 
the Order of the Ministry of Education and Science, dated October 31, 2018 No. 604, the State compulsory standard of higher education was approved, that determines the requirements for the content of education with a focus on learning outcomes, the maximum volume of the educational student load, educational level of students, term of studying in organizations of higher and (or) postgraduate education, regardless of the form of ownership and departmental subordination [11].

The documents that perform a regulatory function on the part of the state quality assurance system and being a benchmark for universities in the development of educational programs, are the National Qualifications Framework, the sectoral qualifications framework, and professional standards [9]. They establish the minimum requirements for knowledge, skills, and competencies of personnel trained by universities.

In connection with the academic independence of universities, the State refused to regulate the content of education and transferred the competence to determine the content of educational programs to universities, leaving only the approval of Model educational programs of general education disciplines, which were approved by the Ministry of Education and Science of the Republic of Kazakhstan dated October 31, 2018 No. 603 [12] that determine the goal, tasks, structure, content, teaching methods for disciplines.

The next block of mechanisms of the State quality assurance system is the establishment of minimum requirements for the organization of the educational process. The basis for the training of personnel with higher education in Kazakhstan is a license to conduct educational activities; licensing is carried out by confirming compliance with the qualification requirements for educational activities [13]. For example, for the implementation of activities in the field of higher education, universities are subject to 18 requirements (compliance of the educational program with the State compulsory standard, requirements for the teaching staff, material and technical base, base of practices, etc.). Based on these requirements, the Criteria for assessing the degree of risk for the education system have been developed [14]. Educational monitoring is carried out with the help of a set of administrative data and analytical assessment indicators for external and internal assessment of the quality of the education system.

Monitoring of educational achievements of students is independent systematic monitoring of the education quality and not dependent on educational organizations.

The third component in the structure of state management for the quality of education is presented in the form of requirements for Accreditation agencies, which are reflected in the Rules for recognition of accreditation bodies, including foreign bodies, and formation of registers of recognized accreditation bodies, accredited educational organizations and educational programs approved by the Order of the Minister of Education and Science of the Republic of Kazakhstan dated November 1, 2016 No. 629 [15]. The state, through the formation of the Register of recognized accreditation bodies (Register 1 ) and the Register of accredited educational organizations (Register 2) and the Register of accredited educational programs (Register 3), indirectly regulates the processes of quality assurance.

Thus, quality assurance management at the state level is carried out by making management decisions and creating regulatory and legal conditions.

\section{External quality assurance of higher education}

The next level of the QA system of higher education is the standards of external quality assurance. In Kazakhstan, these standards are developed by accreditation bodies independently, on the basis of ESG.

It should be noted that according to the legislation in Kazakhstan, the accreditation procedure by educational organizations is voluntary, however, according to the Law "On Education", unaccredited universities do not have the right to issue documents on education (diplomas 
of their own sample - since 2021, universities of Kazakhstan (except medical and military) issue such diplomas) (Article 39) and cannot apply for state funding (Article 62), which makes this procedure mandatory.

Legislation in the field of education does not limit the right of universities to choose an accreditation body (the only requirement is that the agency must be included in the Register 1 ) and the type of accreditation. The organization of education has the right to undergo institutional and (or) specialized (program) accreditation.

The main purpose of institutional accreditation is to obtain confirmation of the readiness of the educational organization to train in accordance with modern requirements imposed on them and the presence of a system aimed at ensuring the quality of the educational process and educational programs. Specialized accreditation - assessment of the quality of educational programs implemented by the organization of education.

According to the requirements [16], to enter Register 1, accreditation bodies must be included in the registers and (or) associations of accreditation bodies of OECD member states: the European Quality Assurance Register (EQAR) or be a full member of the European Association for Quality Assurance in Higher Education. This requirement will allow building a quality assurance system in accordance with European standards and recommendations in the field of quality assurance, thereby ensuring the fulfillment of Kazakhstan's obligation as a member of the Bologna process.

At the same time, accreditation bodies that accredited educational programs of at least two organizations of higher and (or) postgraduate education, included in one of the academic rankings as top 200 ARWU (Academic Ranking of World Universities), top 300 THE (Times Higher Education), top 300 QS World University Rankings, U.S. News and World Report (indicator of a foreign accreditation body, Global Score from 65), can be recognized and included in Register 1 automatically.

As of October 2021, 11 agencies are included in the Register of recognized accreditation bodies of Kazakhstan, including 3 from Germany (FIBAA, ASIIN, ACQUIN), 1 - from Belgium (MusiQuE) and 1 - from the USA (ACBSP). The presence of large foreign players on the market contributes to increased competition.

Register 2 includes 109 organizations of higher and postgraduate education, and the Register 3 - 2384 educational programs of bachelor's degree, 1660 - master's and 462 - PhD's.

These Registers are most likely of a statistical nature and are formed to monitor these phenomena in the education system. But their importance is not diminished by this, since, for example, information about accredited educational organizations indicates that these educational organizations have successfully passed the procedure of recognition on the compliance of educational services with the established standards (regulations) of accreditation. Such information is used when allocating a state educational order, since it is important for the State to allocate the order in universities that provide high-quality educational services.

Accreditation agencies develop their own quality assurance policies and procedures based on the principles of external quality assurance, as well as relevant guidelines and other documents for universities, on the basis of which the latter are prepared for accreditation.

Accreditation agencies have accreditation councils that make final decisions on the approval of Reports on the accreditation of universities and on the accreditation of universities. Therefore, all decisions on accreditation are taken collectively.

Thus, external quality assurance of higher education at the level of accreditation of universities and educational programs of higher and postgraduate education in Kazakhstan is independent. The independence of external quality assurance is due to the fact that it is carried out by independent accreditation agencies according to criteria and standards developed by them independently. 


\section{The system of internal quality assurance of higher education}

The next level of quality assurance systems is internal quality assurance, which is the basis of this structure. The creation of an internal quality assurance system has a legal side. Thus, paragraph 36 of the Standard Rules for the activities of educational organizations implementing educational programs of higher and postgraduate education, approved by the Order of the Ministry of Education and Science of the Republic of Kazakhstan dated October 30,2018 , No. 595 , determines that "in order to improve the quality of educational activities, the university creates a system of internal quality assurance....

With the extending of the independence of Kazakhstani universities, their responsibility for the quality of educational services is strengthened. And the system of internal quality assurance and corporate management begin to play a significant role.

The system of internal quality assurance is based on the principles of quality assurance and on the policy and standards of internal quality assurance, which are developed by the higher education institution independently but based on ESG. Analysis of the websites of universities in Kazakhstan showed that 77 universities have a Quality Assurance Policy (out of 101 universities, the information was formed on the basis of a survey of university websites). In turn, the Standards of internal quality assurance have been developed only in 19 universities. These data indicate a lack of attention of universities, their administration to the system of internal quality assurance. Meanwhile, this is one of the important parameters of the Bologna process, of which the Republic of Kazakhstan is a part.

\section{Design of the national model of quality assurance of higher education}

The design of the National Quality Assurance model can be represented in a threedimensional image. In other words, it is measured and consists, on the one hand of an internal quality assurance system, on the other hand, of an external quality assurance system, and, on the third hand of the management and regulatory mechanisms of the quality assurance system. The main goal of this model for all its three components is to achieve high academic quality, which is referred to as the $Q$ point (quality).

It is important to note that the fundamental principles of the model are: trust and transparency, sustainability and integrity (or unity), focus and adaptability.

In the new architecture of Kazakhstan's higher education quality assurance system, all the necessary institutional foundations and quality assurance tools, as well as assessed and measured materials, have been formed.

The National model of quality assurance of higher education is shown in Figure 2.

The basis of the National Model of Quality Assurance of Higher Education in Kazakhstan (NMQAHE) is the system of internal quality assurance. The indicator of academic quality achievement by the internal quality assurance system is the academic reputation of a higher educational institution.

As you know, academic reputation is the opinion of various categories of community subjects and (or) society, formed about a higher educational institution, based on its academic qualities: achievements, advantages, and disadvantages.

The academic reputation of the university is one of the important indicators of the status and prestige of the university in the education market. There are different methods of assessing academic reputation, for example, different rankings of universities. However, academic reputation is a concept that has a wider range of reflecting the results of the university's activities than rankings. Academic reputation has its own values. Academic reputation reflects the "perceived quality" of the university's educational service by the consumer. 


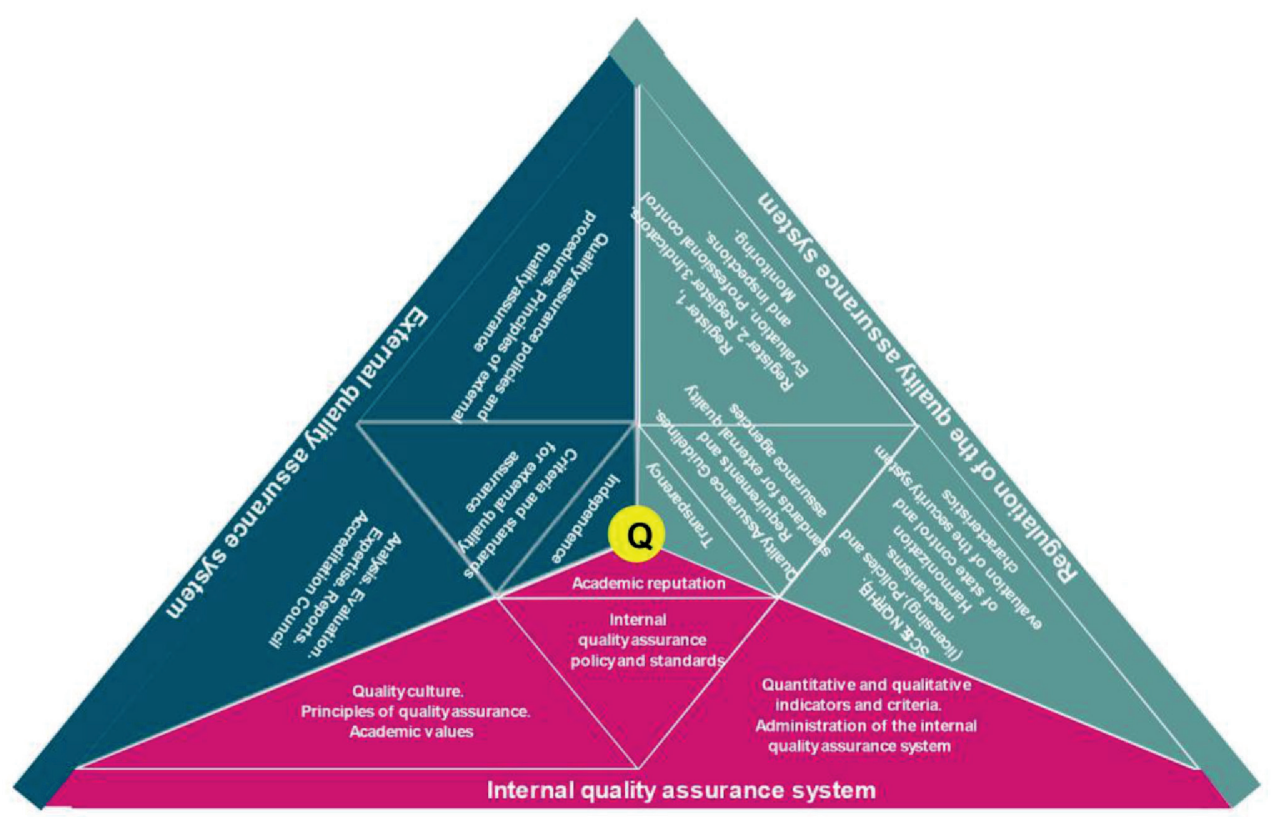

Fig. 2. National model of Quality Assurance of higher education

Academic reputation is measured in accordance with the requests of stakeholders: students, teachers, employees, graduates (so-called reputation ambassadors), civil servants, business, etc.

In this regard, academic reputation is not a retouch, but a real result of the university's activities. To achieve a high academic reputation, the university must really work better and qualitatively, and not only take care of the image. The perfection of academic reputation is achieved with the effectiveness of the internal quality assurance system.

From the point of view of L. Bollaert, before creating an internal quality assurance system, a university should choose a quality concept and define a quality assurance methodology. In accordance with the concept of quality, academic values and a culture of quality are formed within the university.

The internal quality assurance system is based on the principles of quality assurance and on the policy and standards of internal quality assurance, which are developed by the higher education institution independently.

In this regard, it is not enough for universities to have only a developed Policy in the field of quality assurance, but it is also necessary to adopt Internal Quality assurance Standards, according to the requirements of paragraph 36 of the above-mentioned Model Rules.

University standards of internal quality assurance should be developed in accordance with ESG, and consider national priorities, features, tasks solved by the higher education system.

In Standard 1 "Policy for Quality Assurance" it is advisable to indicate anti-corruption measures and the principle of "zero tolerance for corruption", the creation of a special structural unit that administers the internal quality assurance system. Standard 2 "Design and approval of programs" it is necessary to reflect academic and managerial independence, the adopted algorithm for the development, review, evaluation and approval of educational programs, the presence of Academic committees involved in the development of educational programs, the procedure for including educational programs in the republican Register of educational programs. In Standard 4 "Student Admission, progression, recognition and certification" it is preferrable to include the principles of recognition of learning outcomes of formal, informal, and non-formal learning, which became quite possible in accordance with the Concept of Lifelong Learning (continuing education), approved by the Decree of the Government of the 
Republic of Kazakhstan dated July 8, 2021, No. 471. In Standard 5 "Teaching staff" it is necessary to reflect the legislative norms for the admission and dismissal of employees of the Labor Code of the Republic of Kazakhstan, the qualification requirements for the teaching staff of universities, approved by the Order of the Ministry of Education and Science of the Republic of Kazakhstan dated June 17, 2015, No. 391. Standard 6 "Learning resources and student support" should describe the conditions for providing students with a dormitory in accordance with the Qualification requirements for educational activities and a list of documents confirming compliance with them, approved by the Order of the Minister of Education and Science of the Republic of Kazakhstan dated June 17, 2015, No. 391. And, thus, it is necessary to harmonize the standards of internal quality assurance with the current regulatory legal acts regulating the sphere of higher education.

The internal quality assurance system is reflected in quantitative and qualitative indicators and criteria that characterize its "present status".

In the internal quality assurance system, the administration of all its processes and procedures is important. In this regard, each higher education institution should develop its own internal quality assurance system and create conditions for its continuous development, improvement, updating, adjustment, depending on the mission and vision of the university's development for the long-term period. That is, to make it adaptive and purposeful. At the same time, it is very important to have a quality culture in the focus of attention. This is the phenomenon without which other quality assurance mechanisms and tools will not work.

And only a well-formed quality culture within the university will testify to an effectively functioning internal quality assurance system. The university, only with a well-established internal quality assurance system, can move to the next stage (level) of quality assurance - external quality assurance, because at this stage an independent, and therefore objective external assessment of the quality assurance system formed within the university is carried out.

The independence of external quality assurance is since it is carried out by independent accreditation agencies according to criteria and standards developed by them independently. At the same time, it is important that the Standards and Guidelines for external quality assurance not only comply with ESG, but also reflect the priority tasks facing the Kazakh higher education system. In turn, the standards of external quality assurance should be harmonized with the national policy in the field of education and regulatory legal acts regulating higher education. In this case, external quality assurance will complement the state policy in the field of education.

Accreditation agencies develop their own quality assurance policies and procedures based on the principles of external quality assurance, as well as relevant guidelines and other documents for universities, based on which the latter prepare for accreditation. In the work of accreditation agencies, in-depth analysis, thorough evaluation, qualified expertise of the activities of universities and their internal quality assurance systems are important. At the same time, if the university does not have an internal quality assurance system, then the accreditation agency should not give a positive conclusion and accredit this university. This is fundamentally and very important! Otherwise, the principle of integrity (unity) of the quality assurance system will not work.

Accreditation councils' function under accreditation agencies, which make final decisions on the approval of reports on the accreditation of universities and on the accreditation of universities.

The policy for quality assurance of higher education is carried out not only at the university level but also at the national level through regulatory mechanisms. The State forms a national model of quality assurance, which should be sustainable, transparent, and understandable to every subject of the educational process. The need for state regulation of the quality assurance 
system is because it (auth. - the state) protects the interests of citizens in obtaining affordable and high-quality higher education.

The State policy is based on the Quality Assurance Guidelines and on the requirements and standards for external quality assurance agencies. This policy is based primarily on state compulsory education standards, the National Higher Education Qualifications Framework, qualification requirements for educational activities (licensing). This is of no small importance since each country has its own national characteristics, its own national priorities, its own development strategy. In the end, any policy is carried out (or rather should be carried out) considering national interests and mentality. Such a policy will always find support in a wide circle and inspire confidence.

World practice shows that the most effective way to improve the quality of education is indirect regulation of all processes of education quality. In this regard, the transition from the system of state control to the system of quality assurance is underway. At the initial stage, this process was institutionalized by renaming the state body - the Committee for Quality Assurance in the Field of Education and Science.

Now it is necessary to start the process of harmonization of state control and evaluation with the quality assurance system by revising the control and verification procedures and processes of state control, its evaluation indicators, and criteria. The state's interests should move closer and closer to universities, accreditation agencies, and other subjects of the educational market. Since they all have one common goal - to achieve high academic quality, the implementation of which is impossible without unity of interests.

The Ministry of Education and Science should trust those accreditation agencies that are included in this Register. It is no coincidence that cooperation in the field of quality assurance is being developed throughout the European Higher Education Area with the aim of mutual trust. The Ministers of Education of the participating countries of the Bologna Process have agreed that they will trust the quality assurance agencies of the participating countries included in the European Register of Quality Assurance Agencies (EQAR).

\section{Conclusion}

As noted above, all levels of the quality assurance system are aimed at achieving academic quality. In this regard, the principles, mechanisms, and tools of the quality assurance system at all its levels should be interconnected and interact with each other. Only in this case, it becomes possible to improve the quality of higher education. If some element of the quality assurance mechanism does not work, it will be difficult to solve the issues of improving the quality of education. In particular, the lack of a culture of quality among all subjects of the educational process will not really improve the quality of education since evaluation tools will indicate a low interest of individual parties in improving the quality of education. The competitive advantage of a modern university is the ability to quickly adapt to external structural changes in the field of legislation, international tendency, and priority trends.

Thus, the successful functioning of the national quality assurance model is achieved only with the coordinated work of quality assurance mechanisms at all levels of educational activity management and the process of assessing its quality.

\section{References}

1. The National project "Quality Education "Educated Nation". Resolution of the Government of the Republic of Kazakhstan dated October 12, 2021, No. 726. https://www.adilet.zan.kz/rus/docs/ P2100000726. 
2. The Concept of Lifelong Learning (Continuing Education). Resolution of the Government of the Republic of Kazakhstan dated July 8, 2021, No. 471. https://www.adilet.zan.kz/rus/docs/ P2100000471.

3. Constitution of the Republic of Kazakhstan. Adopted on August 30,1995 at the republican referendum. https://adilet.zan.kz/eng/docs/K950001000

4. Law of the Republic of Kazakhstan "On Amendments and Additions to Certain Legislative Acts of the Republic of Kazakhstan on expanding the academic and administrative independence of higher education institutions". Adopted on July 4, 2018. https://adilet.zan.kz/rus/docs/Z1800000171

5. Du, G., Yuan, J., Miao, F., \& Wei, P. (2017). Effectiveness of design process of education quality assurance system based on EFQM model. Eurasia Journal of Mathematics, Science and Technology Education, 13(12), 8205-8211. https://doi.org/10.12973/ejmste/80784

6. Starostina, S. E., \& Kazachek, N. A. (2015). Regulatory and Methodological Changes in the System of Higher Education Quality Assurance. Mediterranean Journal of Social Sciences, 6(4), 140-145. Retrieved from https://www.richtmann.org/journal/index.php/mjss/article/view/7357

7. Mazza, E. (2011). Mapping the Implementation and Application of the ESG (MAP-ESG Project): Final Report of the Project Steering Group. ENQA Occasional Papers 17. ENQA (European Association for Quality Assurance in Higher Education). Avenue de Tervuren 36-38-boite 4, 1040 Brussels, Belgium. http://www.enqa.eu/pubs.lasso

8. Bliznyuk, O. V. (2018). Improving the quality assurance processes of higher education in the context of the realization of national interests. Theoretical economics, 3 (45), 49-60.

9. Center of Bologna process and academic mobility of the Ministry of education and science of the Republic of Kazakhstan (2018). The Analytical report on implementation of the principles the Bologna process in the Republic of Kazakhstan. https://enic-kazakhstan.edu.kz/

10. Okae-Adjei, S. (2016). Internal quality assurance in higher education institutions: The case of some selected Ghanaian polytechnics. European Journal of Research in Social Sciences, 4(8).

11. Order of the Minister of Education and Science of the Republic of Kazakhstan dated October 31, 2018 № 604 “On approval of state compulsory educational standards for all levels of education". Registered with the Ministry of Justice of the Republic of Kazakhstan on November 1, 2018 № 17669. https://adilet.zan.kz/eng/docs/N1800017669.

12. National Qualifications framework. Approved by protocol of the Republican Trilateral Commission on social partnership and regulation social and labor relations. March 16, 2016. https://online. zakon.kz/Document/?doc_id=37482171\#pos=6;-106.

13. Order of the Minister of Education and Science of the Republic of Kazakhstan of October 31, 2018 , No. 603. On approval of the model curriculum of general education disciplines for institutions of higher and (or) postgraduate education. Registered with the Ministry of Justice of the Republic of Kazakhstan on October 31, 2018 No. 17651. https://adilet.zan.kz/eng/docs/N1800017651/history.

14. The Law of the Republic of Kazakhstan dated 16 May 2014 No. 202-V. "On Permissions and Notifications". https://adilet.zan.kz/eng/docs/Z1400000202.

15. Joint Order No. 719 of the Acting Minister of Education and Science of the Republic of Kazakhstan dated December 31, 2015 and No. 843 of the Acting Minister of National Economy of the Republic of Kazakhstan dated December 31, 2015, "On the approval of the criteria for assessing the degree of risk and checklists for inspections of the education system". Registered with the Ministry of Justice of the Republic of Kazakhstan on December 31, 2015 No. 12777. https://adilet.zan.kz/rus/ docs/N1500012777.

16. Order of the Minister of Education and Science of the Republic of Kazakhstan dated November 1 , 2016 № 629 "On approval of the Rules for recognition of accreditation bodies, including foreign bodies, and formation of registers of recognized accreditation bodies, accredited educational organizations and educational programs". Registered with the Ministry of Justice of the Republic of Kazakhstan on November 19, 2016, № 14438. https://adilet.zan.kz/eng/docs/N1600014438. 
Главный редактор:

Белощицкий А.А.

Ответственный редактор:

Амиргалиев Б.Е.

Подписано в печать 29.12.2021 г.

Формат 60×84 1/8. Усл.п.л. 4,6.

Тираж 50 экз. Заказ №48.

Отпечатано в ТОО «Шаңырақ-Медиа».

г. Нур-Султан, ул. Кокарал, 2/1, тел. 87077770066.

www.smedia.kz 